\title{
ASSESSING HUMAN ACTIVITIES INFLUENCES ON THE VEGETATION COVER USING TRENDS OF NORMALIZED DIFFERENCE VEGETATION INDEX TIME SERIES: CASE STUDY IN DORNOD PROVINCE
}

\author{
Tsogbadral Khurelbaatar, \\ Doctor (Ph.D) of Geography, Department of Geography, Mongolian National University of Education \\ (MNUE), Ulaanbaatar, Mongolia \\ Badam Ariya, \\ Master of Geography Science, Division of Land use and Land resource research, The Institute of \\ Geography and Geoecology, MAS (IGG), Ulaanbaatar, Mongolia
}

DOI: https://doi.org/10.31435/rsglobal_conf/30112020/7267

\begin{abstract}
Desertification and land degradation are causing a serious environmental problem in Mongolia, with climate change and human activities being major contributors to the land degradation. This study examines whether MODIS NDVI satellite data time series can be used to detect land degradation and regeneration areas in Eastern province of Mongolia. Time series analysis was applied to a 12-year MODIS NDVI satellite data record, based on the hypothesis that the resulting NDVI residual trend vectors would enable successful detection of changes in photosynthetically active vegetation. GIS and statistical analyses were used to estimate the trend of the annual average NDVI for June, July and August from 2006 to 2017. We also examined land cover development and meteorological data for the same period. MODIS land cover products proved suitable for identifying areas of vegetation cover change. Areas showing positive and negative NDVI trends mostly coincided with areas of land cover class change indicating an increase or a decrease in vegetation, respectively. The Dornod was selected as a study site since the area is vulnerable to desertification. The study results reveal an increasing trend in NDVI values in $89.03 \%$ of the total study area and a decreasing trend in NDVI values in $11.07 \%$ from 2006 to 2017. Overall, 11.07\% of the total area, has been affected by desertification. There was a positive moderate correlation between change in precipitation and the NDVI trend in the study area. The study indicates that the effects of precipitation variance on the changes in the trend of the NDVI resulted from more than human activities in the study area.
\end{abstract}

Keywords: Normalized Difference Vegetation Index (NDVI); Pearson correlation; vegetation cover.

Introduction. The cause of desertification is all types of soil degradation and loss of vegetation cover (Kosmas C, Tsara M, Moustakas N, et al. 2003). The biological indicators of desertification are changes of vegetation and mammal diversity, which consists of the ecosystem (Dash, Jalbaa, 2003). The NDVI is selected as one of the biophysical indicators of land degradation assessment in arid areas (FAO \& LADA 2007). Mongolian and international scientists have agreed that long-term decline of vegetation cover is a sign of desertification (Dash et al. 2003; Lantieri, as cited in FAO \& LADA 2007). The NDVI is the estimated result of remote sensing measurements that indicate greenness of the vegetation and patterns of green biomass (Forkel et al. 2013).

The Dornod province is selected as a research site. This research conducted to estimate trends in annual average NDVI from 2006 to 2017 in this area. The NDVI trends and statistical analysis identified in this period.

As above mentioned, a decrease in NDVI is one of the criteria of land degradation and desertification. Thus, aimed to identify the effect of human impacts and climate, to evaluate each of them for spatial analysis.

Research data.

Meteorological data. The distribution of the weather station network is very sparse across Mongolia. These weather stations estimate the monthly precipitation data for the whole area of each soum, which is inadequate to generate a spatial distribution of precipitation monthly with close approximation of scale and accuracy to the NDVI dataset. In order to estimate spatial distribution of 
the amount of precipitation densely distributed precipitation data are needed. Therefore, remotely sensed precipitation data derived from TRMM's (Tropical rainfall measuring mission) were acquired to estimate the annual average accumulated precipitation for June, July and August from 2006 to 2017. TRMM's monthly precipitation 3B43 data were collected for this study. The spatial resolution of this product is a $0.250 x 0.25$ o grid and the temporal resolution is monthly (Huffman 2016). It presents the monthly average precipitation in $\mathrm{mm} /$ hour per pixel of the $0.25 \mathrm{ox} 0.25 \mathrm{o}$ grid.

Normalized Difference Vegetation Index /NDVI/. MODIS satellite data with $1 \mathrm{~km}$ resolution (MOD13A3) used in annual average NDVI for June, July and August from 2006 to 2017.

Vector data. The vector data include roads, settlement areas and herders' seasonal location points, wells, rivers and streams within the selected area. The data acquired were from the "National unified land territory registration" data which has been developed by the Agency of Land Administration and Land Management, Geodesy and Cartography.

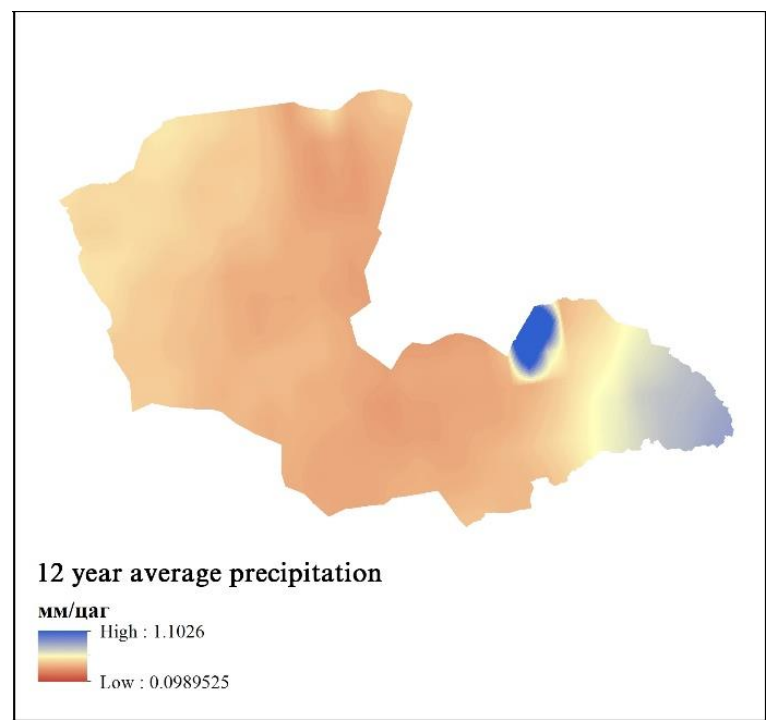

Fig. 1. Spatial distribution of annual precipitation in the Dornod aimag over an average of 12 years

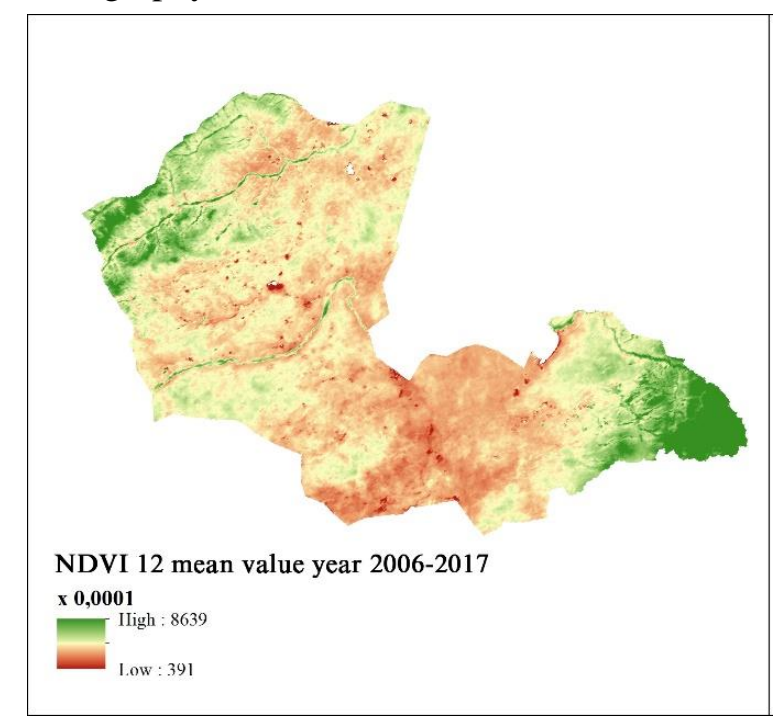

Fig. 2. Spatial distribution of the average NDVI over the 12 years of existence of the Dornod aimag

Data processing. The process was used in ArcGIS 10.3.1 software for spatial analysis and multivariate analysis, transformation.

NDVI. For each year of the study, the values of NDVI/6, 7 and 8 MODIS were superimposed and analyzed according to the average statistical value.

Precipitation. TRMM $3 b 43$ resolution on the surface of the TRMM satellite with a resolution of $0.25^{\circ}$ by gradient in netCDF format to build a clip from the border of the Dornod aimag and to form the spatial distribution of each spatial distribution for each year (up to $1 \mathrm{~km}$ ). The northern end of precipitation is 50 degrees north latitude, no news. In addition, there were no data on the northern sums of sums, such as the sum of Chulluntor from the Dornod aimak. Although the final data were presented in the form of data from meteorological stations, there are few meteorological stations in the area and they are too large and cannot be reconstructed.

Vector data processing. Vector data were converted to $1 \mathrm{~km}$, exactly in 5 districts at a distance of $1 \mathrm{~km}$ from each other for each site, population and wells, wells and rivers.

\section{Research methodology.}

Pearson's correlation analysis. Pearson's correlation determines the degree of linearity between two numerical values. The value of the correlation coefficient is the strength and direction of the connection (positive and negative). The correlation coefficient is expressed in $r$ or $\mathrm{R}$ and varies from [-1: 1]. The Pearson correlation coefficient is measured by linear force ( $r$ ). When we look at the duration of time and variables, we determine the variables. The correlation coefficient measures the strength of the linear relationship, not just the relationship between variables.

For correlation coefficients (Piao \& Fang, 2002), [2] the correlation between NDVI and the given time corresponds to: 


$$
r_{x t}=\frac{\sum_{i=1}^{n}\left(x_{i}-\bar{x}\right)(i-\bar{t})}{\sqrt{\sum_{i=1}^{n}\left(x_{i}-\bar{x}\right)^{2} \sum_{i=1}^{n}(i-\bar{t})^{2}}}
$$

Here is the $n$-shaped year, the value of $x i-i$ is the year of NDVI, (x) is the average value of the given time of NDVI. $\mathrm{t}^{-}$- annual average $(\mathrm{n}+1) / 2$ consecutive years. This value is calculated at each point within $1 \mathrm{~km}(\mathrm{x}, \mathrm{y})$ of 142727 points. Estimated positive and negative values reflect a 12-year decline in the growth rate of the NDVI index over the period 2006-2017.

Results.

NDVI and the precipitation approach. The following figure shows that the mean values of precipitation and NDVI change with each other in the same deviation of the linear correlation line. The NDVI is the most commonly used index and has a measurement scale ranging from -1 to +1 . Negative values represent non-vegetated surfaces, whereas values close to 1 have very dense vegetation (Ioan et al. 2013).

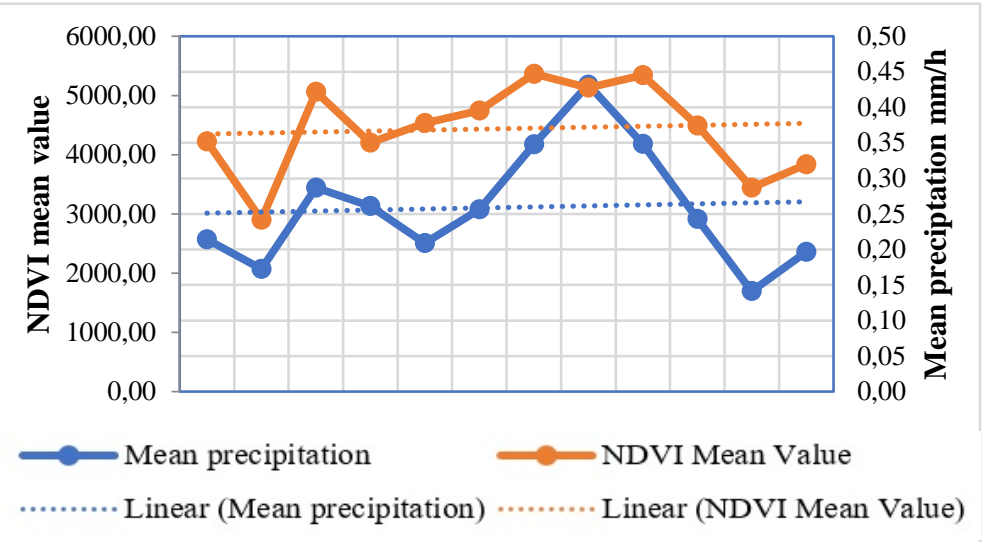

Fig. 3. Comparison of mean 12-year precipitation and mean annual changes in NDVI

The value of the NDVI index and the 12-year significance coefficient or correlation coefficient 1 , the linear dependence with a strong increase, indicates the strength up to the value close to -1. In other words, the linear dependence on strong growth represents a long-term trend of NDVI variables and a significant decrease in the long-term decrease of NDVI variables.

Figure 5 shows that most regions of the country tend to grow moderately or weakly. The slightest tendency is observed to the least extent.

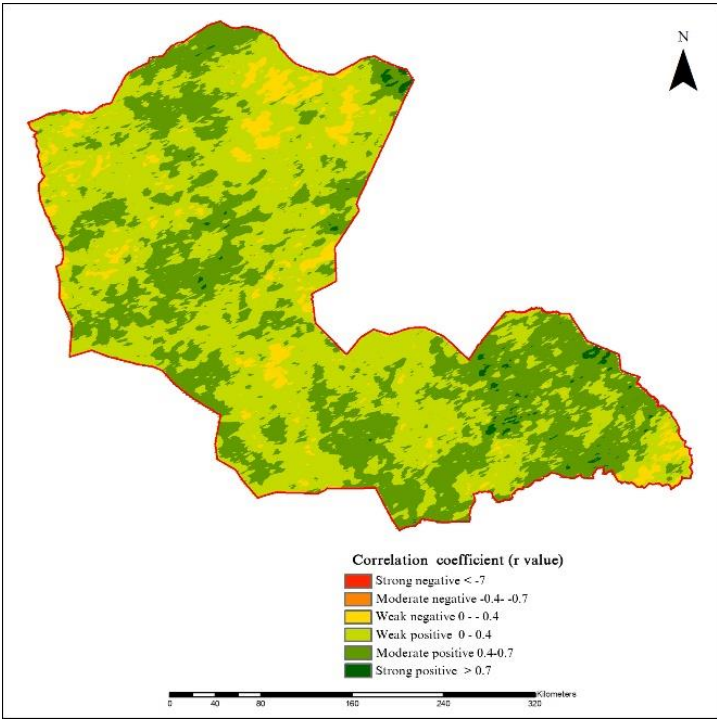

Fig. 4. Value of NDVI and 12-year series of dependences

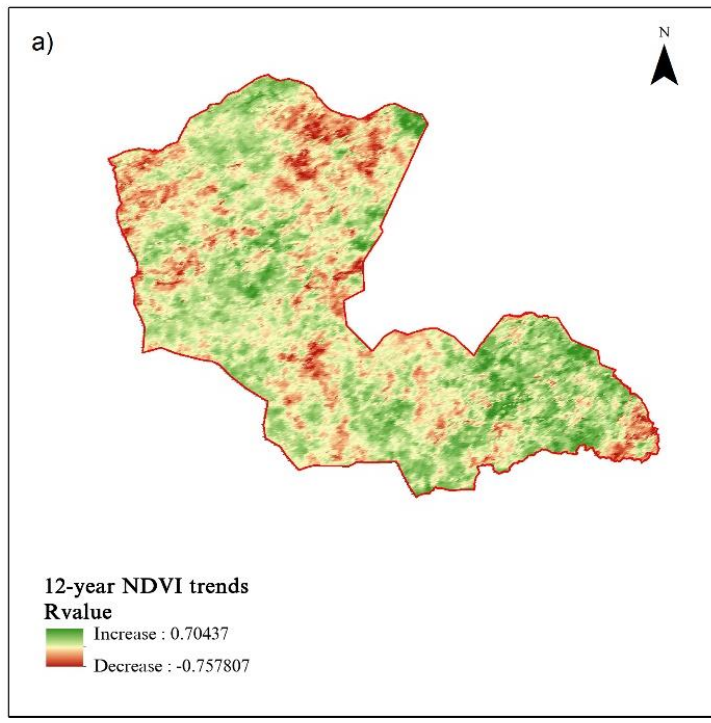

Fig. 5. Comparison of 12-year NDVI trends

(Strength of linear dependence (Value of NDVI and 12-year series of dependences)) 


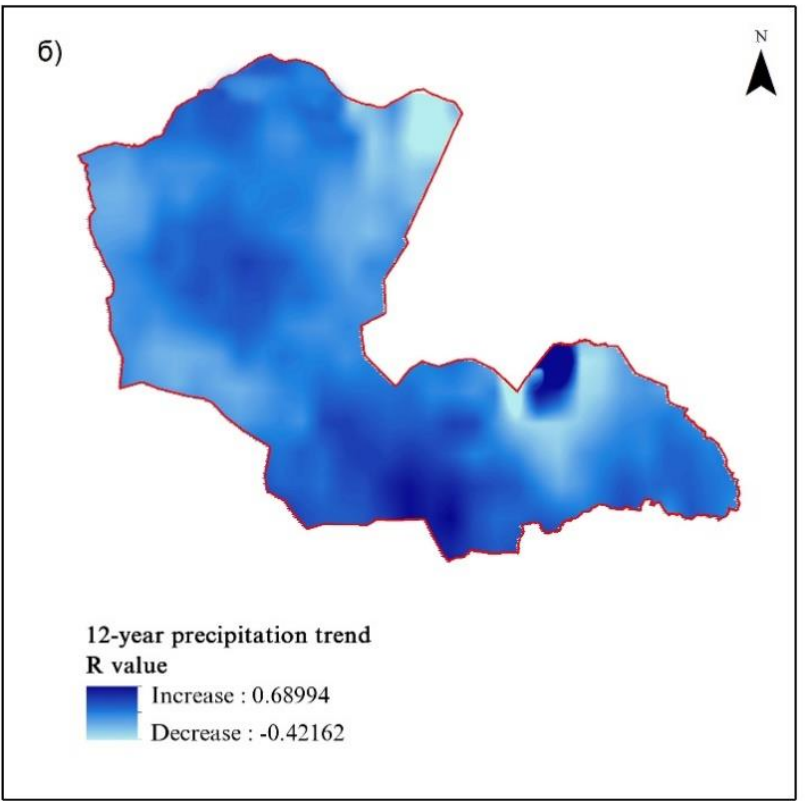

Fig. 6. Trends in precipitation over 12 years

The above graph shows that the amount of precipitation has increased over the past 12 years

\section{Human impacts.}

To ensure the spatial distribution of the human factor, five areas have been identified with an accuracy of $1 \mathrm{~km}$ for humanitarian activities, infrastructure and natural sites, and areas beyond $5 \mathrm{~km}$ are considered less vulnerable to human impact (Figure 7).

Water bodies and their surroundings are the main summer habitat for reindeer herders and represent areas of high intensity. To estimate the anthropogenic impact, the percentage of INR growth within a $5 \mathrm{~km}$ radius of the reservoir is calculated as $1 \mathrm{~km}$ per capita. As can be seen from Table 1 , the maximum reduction of the lake area, or $21 \%$ of the total area, has been reduced.

Infrastructure inflow affects the land types in the Dornod aimag category, such as roads, urban and agricultural areas, and Table 2 shows that the greatest impact in the affected area is $1 \mathrm{~km}$ in the area of impact, occupying 20 percent of the area.

Depending on the type of impact zone, Figure 11 illustrates how NDVI increases and decreases. In terms of total area, the spatial distribution of IRIS trends is $21 \%$ and $17.4 \%$ is in close proximity to the areas under crops.

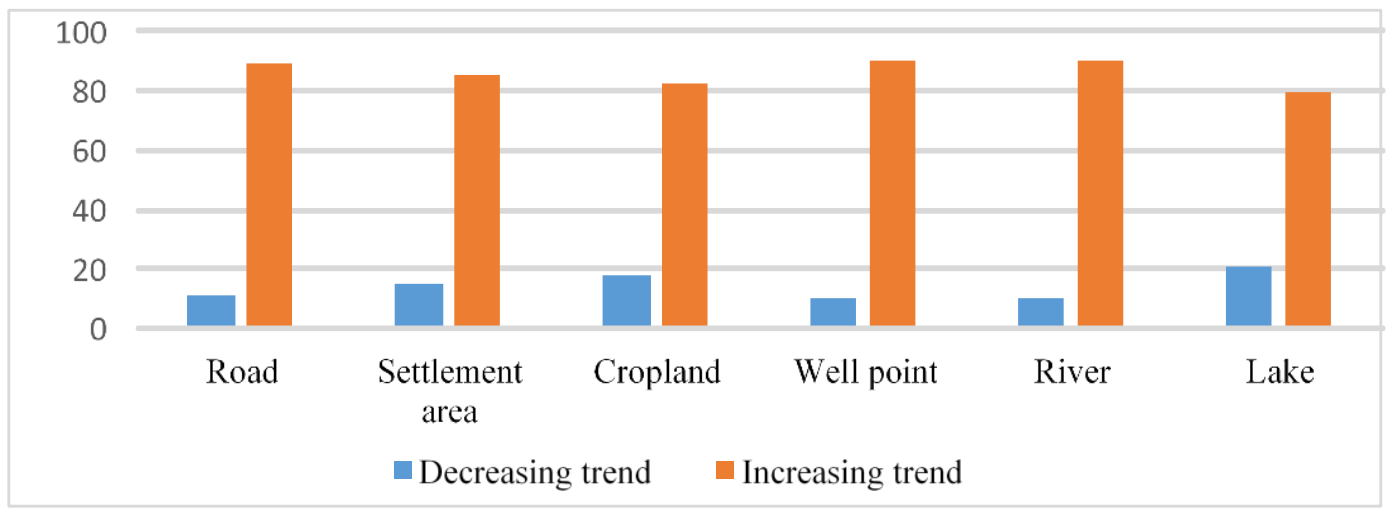

Fig. 7. Ratio of growth rate to NDVI index decrease in the area of influence

\section{Discussion.}

1. According to the correlation coefficient, $11.07 \%$ of the total study area decreased the value of INRRRR. In other words, $11.07 \%$ of the surveyed areas show that vegetation cover is likely to decrease slightly, indicating land degradation and desertification in these areas. Most of the settlement (89.03 percent) is observed, which is directly related to the increase in precipitation over a 12-year period. 
Table 1. Percentage of spatial distribution of IRI trends on river pastures, lakes and ponds in the stream impact zone

\begin{tabular}{|c|c|c|c|c|c|c|c|c|c|c|c|}
\hline \multirow[b]{2}{*}{$\begin{array}{c}\text { Land use } \\
\text { type }\end{array}$} & \multirow[b]{2}{*}{ Trend } & \multicolumn{2}{|c|}{1 kilometer } & \multicolumn{2}{|c|}{$2 \mathrm{~km}$} & \multicolumn{2}{|c|}{$3 \mathrm{~km}$} & \multicolumn{2}{|c|}{$4 \mathrm{~km}$} & \multicolumn{2}{|c|}{$5 \mathrm{~km}$} \\
\hline & & $\begin{array}{l}\text { Total } \\
\text { value }\end{array}$ & Percent & $\begin{array}{l}\text { Total } \\
\text { value }\end{array}$ & Percent & $\begin{array}{l}\text { Total } \\
\text { value }\end{array}$ & Percent & $\begin{array}{l}\text { Total } \\
\text { value }\end{array}$ & Percent & $\begin{array}{c}\text { Total } \\
\text { value }\end{array}$ & Percent \\
\hline \multirow{2}{*}{ Well } & decrease & 730 & 5.45 & 1672 & 11.66 & 1812 & 11.30 & 1685 & 11.32 & 1458 & 11.0 \\
\hline & Increase & 12673 & 94.55 & 12673 & 88.34 & 14223 & 88.70 & 13206 & 88.68 & 11787 & 88.9 \\
\hline \multirow{2}{*}{ River } & decrease & 662 & 14.63 & 559 & 15.34 & 492 & 13.96 & 477 & 13.80 & 478 & 14.3 \\
\hline & Increase & 3864 & 85.37 & 3085 & 84.66 & 3033 & 86.04 & 2980 & 86.20 & 2852 & 85.6 \\
\hline \multirow{2}{*}{ Lake } & decrease & 72 & 18.09 & 99 & 22.81 & 109 & 21.25 & 124 & 20.63 & 137 & 21.0 \\
\hline & Increase & 326 & 81.91 & 335 & 77.19 & 404 & 78.75 & 477 & 79.37 & 514 & 78.9 \\
\hline
\end{tabular}

Table 2. Spatial distribution of HDI trends in anthropogenic factors affecting infrastructure

\begin{tabular}{|c|c|c|c|c|c|c|c|c|c|c|c|}
\hline \multirow[b]{2}{*}{ Type } & \multirow[b]{2}{*}{ Trend } & \multicolumn{2}{|c|}{1 kilometer } & \multicolumn{2}{|c|}{$2 \mathrm{~km}$} & \multicolumn{2}{|c|}{$3 \mathrm{~km}$} & \multicolumn{2}{|c|}{$4 \mathrm{~km}$} & \multicolumn{2}{|c|}{$5 \mathrm{~km}$} \\
\hline & & $\begin{array}{l}\text { Total } \\
\text { value }\end{array}$ & Percent & $\begin{array}{l}\text { Total } \\
\text { value }\end{array}$ & Percent & $\begin{array}{l}\text { Total } \\
\text { value }\end{array}$ & Percent & $\begin{array}{l}\text { Total } \\
\text { value }\end{array}$ & Percent & $\begin{array}{l}\text { Total } \\
\text { value }\end{array}$ & Percent \\
\hline \multirow{2}{*}{ Roads } & decrease & 1311 & 11.4 & 1251 & 11.41 & 1115 & 10.8 & 1067 & 11.1 & 937 & 10.5 \\
\hline & Increase & 10153 & 88.5 & 9716 & 88.59 & 9136 & 89.1 & 8488 & 88.8 & 7942 & 89.4 \\
\hline \multirow{2}{*}{$\begin{array}{c}\text { Settled } \\
\text { area }\end{array}$} & decrease & 71 & 13 & 102 & 14.67 & 112 & 13.6 & 143 & 15.0 & 165 & 15.1 \\
\hline & Increase & 475 & 87 & 593 & 85.32 & 709 & 86.3 & 807 & 84.9 & 921 & 84.8 \\
\hline \multirow{2}{*}{ Cropland } & decrease & 242 & 20 & 251 & 18.24 & 280 & 17.96 & 296 & 17.09 & 288 & 15.11 \\
\hline & Increase & 980 & 80 & 1125 & 81.75 & 1279 & 82.04 & 1436 & 82.91 & 1618 & 84.89 \\
\hline
\end{tabular}

2. The trend correlation $(>0.7)$ and the decrease (<-0.7) are usually very low when estimating the correlation coefficients of correlation coefficients, indicating that over the 12 years between 2007 and 2018 the fluctuations were short.

3. Due to the long-term decrease of the HDI compared to human impact, the impact of aquifers is $20.8 \%$ in lake impact zones, $12.1 \%$ in water impact zones, $10.2-11.1 \%$ in road impact zones, $14.5 \%$ in urban areas and $17.4 \%$ in crop impact zones. However, depending on the type of activity, changes in vegetation cover occur. In the area affected by the water body, especially in the lake area, it is noted that the intensity of traffic in this area is related to shepherds who drink water in summer.

4. As a result of the conducted studies, changes in vegetation cover depend on the influence of precipitation and anthropogenic factors.

Conclusions. The purpose of this study is to review trends based on spatial distribution of vegetation cover, which allows combining spatial analysis of human and natural forces. In addition, indicators that can be used to describe vegetation biomass more realistically in the future are likely to be used to determine vegetation cover and land degradation using the methodology used in this study.

\section{REFERENCES}

1. Dash D., Jalbaa H., Khaulenbeck A., Mandakh N. (2003). Scientific basis for restoration and protection of ecosystems in the Gobi and steppe regions. Geoecological Institute of the Academy of Sciences Mongolia, Research Center on Desertification, Ulaanbaatar

2. FAO, LADA (2007) Technical Report 2, Biophysical indicator toolbox (Pressure/State). Retrieved from http://projects.inweh.unu.edu/kmland/display.php?ID=226\&DISPOP=VRCPR (accessed 1 March 2018).

3. Forkel M, Carvalhais N, Verbesselt J, Mahecha MD, Neigh CSR, Reichstein M (2013) Trend change detection in NDVI time series: Effects of interannual variability and methodology. Remote Sensing 5:2113-2144.

4. Huffman GJ (2016) The Transition in Multi-Satellite products from TRMM to GPM (TMPA to IMERG). Retrieved from https://pmm.nasa.gov/sites/default/files/document_files/TMPA-toIMERG_transition.pdf (accessed 9 March 2017).

5. Ioan P, Bilaşco Ş, Cristina CM, Dîrja M, Moldovan C, Păcurar HM, Lucaci A, Negruşer C (2013) Research on Identification of Degraded Lands in Transylvanian Plateau Using GIS Spatial Analysis 6:216-226.

6. Kosmas C, Tsara M, Moustakas N, et al. (2003). Land desertification and identification indicators. Ann Arid Zones, - 393

7. Piao S, Fang J (2002) Terrestrial net primary production and its Spatio-temporal patterns in QinghaiXizang Plateau, China during 1982-1999. Journal of Natural Resources 17:373-380.

8. Raynolds M, Magnússon B, Metúsalemsson S, Magnússon SH (2015) Warming, Sheep and Volcanoes: Land Cover Changes in Iceland Evident in Satellite NDVI Trends. Remote Sensing, 7(8):9492-9506 